\title{
Fundamentos da Lógica Extensional em Kant e seu Significado para a Lógica Formal
}

\section{Foundations of Extensional Logic in Kant and its meaning to Formal Logic}

Tiago Tranjan*

\begin{abstract}
Resumo: A distinção entre lógica formal e lógica transcendental é uma das maiores conquistas da filosofia crítica de Kant. Por meio de uma análise detalhada da teoria kantiana do conceito, particularmente em seus aspectos formais, o presente artigo visa articular uma maneira pouco usual, mas bastante fecunda, de compreender essa distinção. O caminho percorrido permitirá jogar luz, também, sobre outro tema de grande importância para a lógica: a noção de extensionalidade.
\end{abstract}

Palavras chave: Lógica kantiana. lógica transcendental. lógica formal. extensionalidade.

\begin{abstract}
The distinction between formal and transcendental logic is one of the greatest achievements of Kant's critical philosophy. By means of a detailed analysis of Kant's concept theory, with special attention to its formal aspects, this paper endeavours to articulate an unusual, though extremely fecund way of understanding this distinction. Our investigation will also shed light over another very important theme for logic: the notion of extensionality.
\end{abstract}

Key words: Kantian logic. transcendental logic. formal logic. extensionality.

Como compreender a distinção, como suposto por boa parte da traoferecida por Kant, entre lógica dição contemporânea?

formal e lógica transcendental? A partir das questões acima, poComo compreender o significado demos extrair um relevante proda lógica formal, à luz dessa se- grama de pesquisa a respeito da lóparação? Finalmente: é possí- gica formal ou, mais precisamente, vel fundamentar adequadamente a dos procedimentos lógico-formais ideia de uma lógica extensional, tal em lógica. Mais uma vez, a cor-

${ }^{\star} \mathrm{O}$ autor é atualmente professor adjunto da Universidade Federal de São Paulo (UNIFESP) 
reta compreensão do legado kantiano mostra-se decisiva para que consigamos ultrapassar o dogmatismo corrente também nessa disciplina, assumindo uma postura verdadeiramente crítica capaz de examinar as condições sob as quais qualquer formalismo pode tornarse parte significativa do discurso.

Neste artigo, oferecemos uma proposta de leitura do legado lógico kantiano, tendo como horizonte as três questões indicadas. Esse é o fio condutor que percorreremos para esboçar certo quadro de impasses postos à lógica formal contemporânea.

\section{O problema geral da referência}

Em uma famosa carta a Marcus Hertz, escrita em 1773, Kant observa:

"Enquanto refletia sobre a parte teórica, (...) percebi que ainda me faltava algo essencial, algo que em meus extensos estudos metafísicos eu, assim como outros além de mim, havia sido incapaz de notar e que, na verdade, constitui a chave para todo o segredo da ainda hoje obscura metafísica. Eu me perguntei: qual é o fun- damento da relação de referência daquilo em nós que chamamos de 'representação' com o objeto?"1

O problema da referência fornece uma das questões centrais que guiará o pensamento de Kant até a filosofia crítica. O que está em jogo, como fica claro na citação acima, é o modo possível da relação entre uma representação, como algo que está no sujeito que representa, e o objeto representado, à medida justamente que toda representação é sempre representação de algo.

Na filosofia crítica, essa relação de referência será examinada por diferentes ângulos. Por um lado, Kant tenta estabelecer a objetividade transcendental da referência, ou seja, a possibilidade a priori que uma representação tem de alcançar algum objeto na experiência. O problema, porém, já não pode ser colocado em termos dogmáticos. Não se trata mais de buscar um acordo, ou sobreposição, entre a representação subjetiva e algum objeto externo a ela. Internalizada, a questão passa a fazer parte de uma crítica imanente da razão. Trata-se agora de encontrar o traço próprio às represen-

1 [Kant, 1759-99]: págs. 129-130. 
tações, por assim dizer interno a elas, que lhes permita representar - e o verbo mais preciso, aqui, talvez seja "constituir" - algo que se possa chamar, a priori, de "objeto".

A questão que se coloca, nesse sentido, é: Quais as categorias necessárias por meio das quais, somente, é possível constituir (representar) uma "realidade", ou seja, um mundo de objetos cognoscíveis? Essa investigação, que é a própria investigação transcendental, ultrapassa o âmbito puramente formal à medida que examina não apenas a forma do conhecimento, mas também seu conteúdo. Mais especificamente, a investigação transcendental volta-se a estabelecer certos conteúdos necessários à cognição discursiva, ou seja, à cognição conceitual de objetos. Volta-se, portanto, a examinar o problema da referência sob um enfoque que ultrapassa o meramente formal, para abranger aspectos materiais dessa referência.

Há, contudo, um segundo aspecto sob o qual Kant considera esse mesmo problema da referência, sem adentrar o terreno do transcendental. Trata-se aqui da investigação puramente formal a algo novo, já a trazemos para o respeito da referência. A pergunta âmbito da nossa consciência, ou

passa a ser: Quais as características formais do conhecimento (dos juízos e dos conceitos) que lhe permitem referir-se a objetos? Para essa investigação, não é preciso indagar pelo conteúdo necessário do conceito objetivo (o conteúdo por meio do qual, somente, o objeto pode ser pensado como tal, e o conhecimento pode atingir algum grau de validade objetiva), mas tãosomente pela forma que permite ao conceito estabelecer uma relação de referência com objetos quaisquer (independentemente de conteúdos).

Vamos explorar um pouco esse tema, e ver como isso é feito em Kant.

\section{Teoria formal do conceito em Kant}

Representações, para Kant, são o produto de uma atividade do entendimento sobre uma multiplicidade dada (em particular, sobre a multiplicidade sensível). Essa atividade é sempre uma sintese: apreendemos a multiplicidade e, quase só por esse mesmo fato - devemos lembrar, aqui, da sintese da apreensão -, já a transformamos em , v.5, n.1, Jul. 2017, p.77-92 
seja, sintetizamo-la como representação. Eis porque toda representação contém uma multiplicidade, e eis também porque toda representação tem um objeto que lhe é próprio: pois o que se apresenta para a síntese é sempre uma multiplicidade, mas o que se representa já é, na medida mesma em que houve uma síntese, objeto.

Como se sabe, Kant apresenta toda uma hierarquia de representações. Não somente intuições (representações singulares) e conceitos (representações gerais) são representações. O que singulariza intuições e conceitos como representações é o fato de eles representarem objetos completamente determinados. Um objeto diz-se completamente determinado se, em relação a todo predicado, está determinado se ele convém ou não ao objeto. É de suma importância entender, neste ponto, que não são as intuições ou conceitos eles mesmos que são - como representações - completamente determinados. Completamente determinados são os objetos que eles representam $^{2}$. É precisamente nesse ponto que reside a objetividade de intuições e conceitos como representações. Sensações são percepções não-objetivas, nesse sentido, não porque lhes careça totalmente um objeto, mas porque o objeto ou objetos a que se referem não são completamente determinados.

Consideremos um pouco mais de perto, agora, o conceito como representação geral. Qual sua forma lógica? A resposta de Kant é: a forma lógica do conceito é a generalidade. Nesse sentido, o conteúdo de uma intuição e de um conceito podem até coincidir; no entanto, a intuição é vista como a representação de um indivíduo, ao passo que o conceito representa uma classe de objetos. Isso porque a forma lógica de ambos difere: um conceito, por sua forma lógica, representa uma classe de objetos. Mas o quê, exatamente, isso quer dizer? E como isso é possível?

O sistema kantiano assume, como um de seus pontos centrais, a ideia de que o juízo tem uma pretensão de conhecimento objetivo. Conhecimento em sentido próprio ocorre somente no juízo,

\footnotetext{
${ }^{2}$ E nem importa, aqui, que esses objetos completamente determinados devam ser eles mesmos, segundo o princípio crítico, outras tantas representações; para Kant, não há mal algum em supor, como limite lógico, representações que sejam completamente determinadas (as "möglische ganzen Vorstellungen").
} 
porque somente no juízo é feita vem possuir alguma característica uma afirmação com pretensão de que lhes permita referir-se a clasvalidade em relação a objetos. A ses de objetos. Essa característica é, objetividade dos juízos, portanto, justamente, a forma lógica do condiz respeito à sua capacidade de ceito: sua generalidade. Trata-se dizer alguma coisa relativa a um de uma característica formal que mundo de objetos. Essa capaci- corresponde ao exercício de certos dade significa duas coisas. Em pri- atos do entendimento. Mais espemeiro lugar, significa que os con- cificamente, há para Kant três atos ceitos ligados em um juízo categórico devem poder referir-se a objetos; mais especificamente, conceitos devem poder referir-se a classes de objetos possíveis. Em segundo lugar, significa que a própria relação entre conceitos é vista, no juízo categórico, como uma relação objetiva (fato esse expresso pela cópula “é"). Eis por que Kant afirma que o conceito, no juízo, é usado como fundamento de conhecimento (Erkenntnisgrund), ou seja, como fundamento da referência objetiva do juízo. Essa utilização do conceito como fundamento de conhecimento é justamente sua utilização como instrumento formal para a referência a objetos.

Para entender o que se passa, consideremos mais de perto as duas exigências mencionadas. A primeira delas, formulada em termos rigorosos, estabelece que con- mente nova, usada como instruceitos, como representações, de- mento para a referência formal a 
objetos: o conceito como representação geral.

Em resumo, podemos ver que o exercício de certos atos lógicos corresponde à construção de certa consciência ligada à representação:

a consciência de que a representação pode ser usada como instrumento formal para referir-se a objetos, ou seja, pode (1) ter a forma da generalidade, (2) ser usada como fundamento de conhecimento, (3) ser um conceito (e o que importa, aqui, é a equivalência entre esses três aspectos).

Diante disso, torna-se simples entender a segunda exigência apontada acima para a objetividade dos juízos. Não apenas os conceitos permitem, por sua forma lógica, a referência a classes de objetos; também a relação estabelecida entre conceitos no juízo categórico é objetiva, na medida em que é uma relação entre as classes de objetos referidas pelos conceitos. Que "todo A é B", agora, não é mais uma afirmação acerca do conteúdo dos conceitos A e B; esse juízo torna-se objetivo - diz alguma coisa a respeito do mundo objetivo - na medida em que afirma uma relação de inclusão, verificada no mundo, entre as classes de objetos referidos mediante cada um dos conceitos envolvidos.

\section{Lógica formal e lógica trans- cendental}

A discussão interpretativa a respeito da relação que se estabelece, no sistema kantiano, entre lógica formal e lógica transcendental é quase tão antiga quanto o próprio sistema kantiano. Para nossos propósitos, é suficiente defender, nesse debate, a seguinte tese simples: a forma lógica do conceito não depende, quanto à sua origem e natureza, dos resultados da investigação transcendental.

Para fundamentar essa posição, devemos considerar a definição kantiana de lógica em seu sentido mais amplo: como ciência das leis do entendimento. O entendimento exerce uma atividade que, aliada à passividade sensível, permite a obtenção de conhecimento objetivo. Nesse fato está envolvida a idéia de que, considerada em seu resultado final, tal atividade consegue referir-se a objetos (por meio de conceitos) e, mais ainda, consegue dar-se objetos a priori.

Nesse sentido, de fato, o objeto possível, que constitui a referên- 
cia de um conceito qualquer, só é obtido como uma ligação (Verbindung) da multiplicidade em geral, ou seja, por meio de uma síntese da multiplicidade em geral, atividade esta que deve ser compreendida sob o enfoque transcendental. Considerada em seu resultado final, portanto, a generalidade do conceito tem mesmo de remeter a uma classe de objetos revelados pela lógica transcendental. No entanto, também a generalidade do conceito resulta diretamente da maneira como se exerce a atividade do entendimento, no momento em que faz nascer o conceito quanto à forma. A generalidade é assim uma característica formal que diz respeito à maneira como o entendimento transforma analiticamente uma representação em conceito (e que envolve os três momentos descritos acima).

Pode-se compreender, assim, o aspecto independente e complementar que caracteriza, ao menos neste passo, a relação entre as duas lógicas. Ambas tratam das regras do entendimento, que conjuntamente operam para permitir o conhecimento objetivo. Essas regras, mais ainda, devem ser obtidas analiticamente do exame da natureza do entendimento. No exame proposto por Kant, descobrem-se dois conjuntos de regras, a que chamamos formais e transcendentais. Segue dessa própria maneira de colocar o problema, porém, que um conjunto de regras não deriva de outro, pois ambos derivam da natureza do entendimento, e devem ser descobertos de um princípio mais alto, concernente à natureza do entendimento (esse princípio, de resto, é a unidade sintética da apercepção). Se considerarmos, assim, que ambos os conjuntos de regras desempenham, como regras do entendimento, uma função específica e indispensável à obtenção do conhecimento objetivo, então não será surpresa que o objeto possível, ao qual se liga o conceito em sua generalidade, seja necessariamente o resultado de um desses conjuntos de regras, capaz de estabelecer o conteúdo mínimo do conceito a priori. Mas isso, obviamente, não revela nenhuma relação de dependência entre as regras. E se é verdade que a lógica formal, sem a lógica transcendental, não consegue dar-se um objeto a priori, é igualmente verdade que a última, sem a primeira, não consegue resolver plenamente o pro- 
blema da referência, pois seria incapaz de se estruturar em um sistema formal. A pergunta pela dependência, nesse sentido, mostrase essencialmente mal-formulada.

Para resumir, podemos dizer que o resultado final da atividade do entendimento, quando opera por conceitos, é a referência a uma classe de objetos, pensados necessariamente segundo as categorias. Pode-se considerar essa atividade, como temos insistido, sob os dois aspectos distintos da referência. Sob o aspecto formal, o que importa é a generalidade do conceito, ou seja, a ligação a uma diversidade de objetos (referência formal); sob o aspecto transcendental, o que importa é a determinação das categorias, ou seja, do conteúdo mínimo de qualquer referência objetiva (objetividade transcendental da referência). E podemos adiantar: o aspecto transcendental do problema da referência, a que estamos chamando sua objetividade transcendental, diz respeito à aplicabilidade do sistema formal. Trata-se em geral de considerar como uma forma lógica - no caso, a do conceito - pode aplicarse à realidade.

\section{A lógica formal kantiana como} lógica extensional

Mais célebre do que a carta a Hertz, com que começamos este artigo, é a passagem da Crítica da Razão Pura em que Kant comenta acerca do destino da lógica aristotélica. Completa e acabada, ela não poderia dar nenhum passo atrás, nem nenhum passo à frente. De fato, ao resolver o problema da referência formal a objetos do modo como descrevemos acima, Kant filia-se diretamente à tradição aristotélica. Sua lógica formal é uma lógica de classes. Contudo, ele oferece para essa tradição um fundamento novo, em certa medida oposto àquele que preside todo o pensamento do Estagirita.

Para Kant, qualquer questão relativa ao conteúdo dos conceitos é irrelevante quando se trata de examinar sua forma lógica, que é a generalidade. A forma da generalidade, como vimos, é obtida por meio de três atos do entendimento: comparação, reflexão e abstração. Esses três atos são absolutamente indiferentes ao conteúdo específico de um conceito. Central aqui é o ato da reflexão: a tomada de consciência de que certa representação 
pode referir-se a diferentes objetos, cada um deles visto como completamente determinado. É assim que ela se torna uma representação geral (conceito), passível de ser usada como fundamento de conhecimento em um juízo capaz de falar de uma realidade objetiva. Como representação, o conceito é dado na consciência; mas como fundamento de conhecimento em um juízo, ele se refere a uma classe de objetos.

Opera-se aqui um salto: do conceito como representação geral para uma classe de objetos na realidade. Pelo ato da abstração, o conceito ignora (abstrai) os outros predicados que cada objeto possa ter, como objeto completamente determinado. Em outras palavras: o conceito é indiferente, por sua forma lógica, à completude do objeto.

Mas a questão, aqui, desdobrase em um segundo plano. Não apenas o conceito, por sua forma lógica, refere-se sempre a uma classe de objetos. Abandonado nesse ponto, o tratamento do problema permaneceria incompleto. Essencial ainda é o fato de que o conceito é utilizado no juízo como fundamento de conhecimento. Isso sig- mal de referência. Eis também por- 
que a lógica geral revela-se, em Kant, como lógica formal.

A resolução do problema formal da referência corresponde, assim, à estruturação do sistema de lógica formal: a generalidade (referência a classes de objetos) como forma lógica do conceito determina o caráter extensional do juízo e, um passo à frente, toda a estrutura inferencial que se estabelece entre juízos. Corresponde, portanto, à estrutura extensional do sistema de lógica como um todo.

Já sabemos, porém, que o problema formal da referência não é o único aspecto sob o qual a questão da referência é considerada na filosofia crítica. $\mathrm{Na}$ verdade, central para o projeto crítico - porque definidor de sua especificidade como projeto filosófico - é o problema transcendental da referência (sua objetividade transcendental). Esse problema, por sua vez, corresponde à indagação pela aplicabilidade do conhecimento discursivo (conceitualmente articulado) e, portanto, à aplicabilidade do sistema lógicoformal. Nesse ponto, a pergunta deixa de ser: "Qual a forma lógica que permite a referência a objetos?", para tornar-se: "Qual o as- pecto da lógica (da atividade do entendimento) que garante a referência a priori a objetos?", ou seja, "Como é possível garantir a priori a aplicabilidade do sistema lógicoformal a alguma coisa que possa efetivamente ser chamada de objeto e, mais geralmente, à realidade?".

\section{Lógica transcendental como} lógica da aplicabilidade de sistemas formais

Retornamos então ao problema da separação entre lógica formal e lógica transcendental. Acreditamos já ter esclarecido o tipo de independência que deve reger a relação entre ambas, dados os pressupostos do projeto crítico kantiano como analítica do entendimento. Estamos agora em condições de avaliar a riqueza de consequências dessa separação - e até mesmo de criticá-la.

A separação entre lógica formal e lógica transcendental está intrinsecamente associada, na filosofia kantiana, a uma nova postura epistemológica e ontológica, que afasta a ideia de substância do centro da investigação ontológica, ao mesmo tempo em que afasta a isomorfia entre conceito e coisa do centro da 
investigação epistemológica ${ }^{3}$. Há este: o problema da aplicabilidade em Kant uma ruptura profunda do de um sistema formalmente determiimplexo tradicional entre lógica, nado. É certo que a questão é suontologia e epistemologia, cujo al- ficientemente ampla para admitir cance seria difícil superestimar. mais de uma resposta. Em espe-

Mas essa ruptura deve ser examinada, segundo a exposição que fizemos, sob um duplo aspecto, capaz de sublinhar não apenas um, mas os dois polos de que deriva. Por um lado, encontramos em Kant a elaboração minuciosa de uma nova fundamentação para o caráter extensional da lógica. Essa é uma investigação formal da lógica, visando a estabelecer a estrutura da referência formal a objetos, por meio do conceito, no juízo. Tratase do lado formal do problema da referência, frequentemente esquecido.

Por outro lado, esse movimento é acompanhado pela proposição de um novo tipo de investigação lógica, vale dizer, de um novo campo de indagação que coube a Kant descortinar: a lógica transcendental.

Mas podemos agora perguntar: Kant. Isso é feito de um modo Qual o problema central da lógica bastante específico, que começa transcendental? A nós, parece ser com uma investigação categorial-

\footnotetext{
${ }^{3}$ A esse respeito, ver o estudo detalhado de Schulthess, em [Schulthess, 1981].

4 Para uma ênfase típica nessa formulação, ver, por exemplo, [Grayeff, 1951] e [Hanna, 2001].
} 
transcendental e prossegue, para muito além, na determinação de princípios transcendentais etc. Em outras palavras: tendo desfeito o implexo lógica-ontologiaepistemologia, Kant opta por construir de modo bastante específico a parte positiva de seu sistema, por meio de uma análise transcendental que deve conduzir a resultados bem definidos. Kant deseja obter uma solução para seu problema: em especial, ele deseja garantir - e daí deriva, justamente, a exigência de apriorismo - a aplicabilidade do específico sistema de lógica formal que tem em mãos. Em outras palavras, ele deseja garantir a priori a referência material a objetos (problema transcendental da referência, para o qual Kant oferece uma resposta forte).

Contudo, podemos agora ressaltar que nem o sentido nem o destino do problema lógicotranscendental, na formulação mais ampla que adotamos, dependem da particular solução que Kant julga ter-lhe encontrado.

Podemos também observar, como consequência natural da nossa proposta, que a separação entre lógica formal e lógica transcendental corresponde à separação entre, de um lado, o desenvolvimento de um sistema de lógica formal como base da estrutura discursiva e, de outro, considerações de natureza epistemológica e ontológica em geral. Isso porque as considerações desse último tipo ficam plenamente absorvidas pela problemática transcendental tal como apresentada acima, ou seja, pelo problema da aplicação do sistema formal.

Finalmente, podemos compreender que, do ponto de vista estritamente formal, já não importa determinar - como parte de uma teoria da estrutura discursiva - a suposta estrutura ontológica dos objetos de conhecimento (dos objetos de referência do discurso), nem importa determinar o modo como é possível conhecê-los (ou mesmo se é possível conhecê-los). O que importa, somente, é que esses objetos, considerados como objetos completamente determinados - como unidades no mundo -, podem ser formalmente referidos pelo discurso.

\section{O legado de Kant para a lógica formal}

Os resultados expostos acima podem ser resumidos assim: 1) Em 
Kant, o problema central da refe- sófica. Colocada no âmbito da rência desdobra-se em dois: o pro- linguagem - um âmbito propriablema formal e o problema trans- mente social, logicamente incomcendental. 2) Ao resolver o pro- patível com qualquer ideia de uma blema formal da referência, Kant subjetividade pura -, essa questão chega a uma abordagem extensi- diz respeito, exatamente, ao sigonal para a lógica. 3) A separa- nificado das práticas formalizanção entre o momento formal e o tes típicas da lógica matemática, momento transcendental da lógica tal como passou a ser desenvolcorresponde a uma separação radi- vida a partir de finais do século cal entre questões de lógica formal, XIX, e da própria prática matemáde um lado, e questões epistemológicas e ontológicas, de outro. 4) Essa mesma separação permite ver o problema fundamental da lógica transcendental, da maneira mais geral possível, como o problema da aplicabilidade de um sistema formalmente determinado.

Vale a pena agora perguntar: Será aceitável a fundamentação kantiana para uma lógica formalmente extensional, em que o problema formal da referência é examinado de maneira separada e independente do problema transcendental da referência, ou seja, independente das condições de sua aplicabilidade?

Eis uma questão de imensa relevância que deveria deslocar-se para o centro da atenção filotica que lhe serviu de modelo, baseada em certa autonomia do simbolismo que remonta ao menos ao século $\mathrm{XV}^{5}$. Diz respeito, portanto, ao valor e significado da lógica formal, como construção de sistemas idealmente regrados e formalmente fechados, em face das necessidades de aplicação desses sistemas. E aqui se revela o fato problemático por excelência, o qual convida a um tipo bastante particular de curto-circuito, que necessita ser corretamente avaliado: superada a ingenuidade de uma homologa natural entre mundo e discurso, a estruturação de sistemas formais só faz sentido a partir da separação kantiana entre momento formal e momento transcendental; mas a aplicação dos sistemas for-

\footnotetext{
${ }^{5}$ A esse respeito, ver [Klein, 1934] e [Mehrtens, 1990].
} 
mais, a quaisquer fins a que se ções explícitas de seus praticantes. destinem, só pode ser examinada, A essencial liberdade no desenem última instância, como parte de volvimento de cálculos simbólicos, uma prática linguística mais am- que prevalece inequivocamente ao pla, não-formalizada, em que a se- menos desde a década de 1940, só paração entre momento formal e é compreensível à luz dessa sepamomento transcendental - duali- ração, no exato sentido que busdade essa que reaparece sob ou- camos destacar. Para muito além tros disfarces: forma e conteúdo, das limitações usualmente apontasintaxe e semântica etc. - perde das à lógica formal kantiana ${ }^{6}$, o progressivamente seu sentido e sua desenvolvimento da concepção crípossibilidade. tica permitiu dar um passo deter-

Mas retornemos a Kant. Do minante para a correta formulação ponto de vista histórico, cumpre da problemática lógico-formal. E reconhecer que a separação pro- a adequada compreensão desse lemovida por ele entre lógica formal gado, nas linhas propostas acima, é e lógica transcendental tornou-se essencial para a avaliação das prádeterminante para o modo como a ticas contemporâneas nessa discilógica formal veio a ser desenvol- plina, bem como de suas pretenvida a partir do século XX, em mui- sões.

tos casos a despeito das declara-

\section{Referências bibliográficas}

BARONE, F. Logica Formale e Logica Trascendentale; Edizioni di Filosofia: Turim, 1964 ( $2^{\mathrm{a}}$ edição).

COFFA, A. The Semantic Tradition from Kant to Carnap: to the Vienna Station; Cambridge University Press: Cambridge, 1991. GRAYEFF, F. Exposição e Interpretação da Filosofia Teórica de Kant; Edições 70: Lisboa, 1987.

${ }^{6}$ Um bom resumo dessa questão é dado em [Barone, 1957] 
HANNA, R. Kant e os Fundamentos da Filosofia Analítica; Editora Unisinos: São Leopoldo, 2004. HUSSERL, E. Formale und transzendentale Logik: Versuch einer Kritik der logischen Vernunft; Max Niemeyer Verlag: Halle, 1929.

KANT, I. Kritik der reinen Vernunft; Suhrkamp: Frankfurt, 1974.

Logik; Kant's gesammelte Schriften, herausgegeben von der Königlich Preussischen Akademie der Wissenschaften, Band IX: Berlim e Leipzig, 1923. Kant's Briefwechsel; Kant's gesammelte Schriften, herausgegeben von der Königlich Preussischen Akademie der Wissenschaften, Band XI: Berlim e Leipzig, 1922. Kant's handschriftlicher Nachlass, Band III, Logik; Kant's gesammelte Schriften, herausgegeben von der Königlich Preussischen Akademie der Wissenschaften, Band XVI: Berlim e Leipzig, 1924. Kant's Vorlesungen, Band I, Vorlesungen über Logik; Kant's gesammelte Schriften, herausgegeben von der Königlich Preussischen Akademie der Wissenschaften, Band XXIV: Berlim e Leipzig, 1966.

KLEIN, J. Greek Mathematical Thought and the Origin of Algebra (tradução para o inglês de Eva Brann); Dover: Nova York, 1968. MEHRTENS, H. Moderne, Sprache, Mathematik - eine Geschichte des Streites um die Grundlagen der Disziplin und des Subjekts formaler Systeme; Suhrkamp: Frankfurt, 1990.

PRIEN, B. Kants Logik der Begriffe; Walter de Gruyter: Berlim/Nova York, 2006.

SCHULTHESS, P. Relation und Funktion - eine systematische und entwicklungsgeschichtliche Untersuchung zur theoretischen Philosophie Kants; Walter de Gruyter: Berlim, 1981. 
